\title{
Influence of molar ratio in aminoplastic resins on the dependence of the measured perforator values on the moisture content of wood-based panels
}

\author{
B. Johnsson • B. Engström • E. Roffael
}

Received: 4 November 2010/Published online: 12 March 2011

(C) The Author(s) 2011. This article is published with open access at Springerlink.com

\begin{abstract}
The correction factor developed by Jann and Deppe (1990) to adjust the measured perforator values of particleboards and fibreboards measured at different moisture contents in the range of $3 \% \leq \mathrm{u} \leq 9 \%$ to the level at $6.5 \%$ moisture content has two main deficiencies. It takes no account of the influence of the molar ratio of the resins used, which seems to remarkably impact the relationship between the moisture content and the measured perforator values. Moreover, research work revealed that the correction factor to be applied also depends on the moisture content, at which the perforator value was measured, according to an inversely proportional correlation. Besides, the correction factor according to Jann-Deppe leaves this fact unconsidered.
\end{abstract}

\section{Introduction}

The formaldehyde release from wood-based panels can be assessed using several methods described in the literature (e.g., Roffael 1993, Salthammer et al. 2009). In Europe, the chamber method, according to EN 717-1, is the reference method for measuring the formaldehyde release from composite boards as well as molded products containing formaldehyde-emitting resins. The determination of extractable formaldehyde using the perforator method according to the boundary conditions stipulated in EN (1992) found and still finds widespread application not only in Europe but also worldwide. According to the German guideline (ETB-Richtlinie) enacted in 1980/1981, boards can be classified using the perforator method into E1,

B. Johnsson · B. Engström

Casco Adhesives AB, P O Box 13000, 85013 Sundsvall, Sweden

E. Roffael $(\bowtie)$

Georg-August-Universität Göttingen, Büsgenweg 1, 37077 Göttingen, Germany

e-mail: eroffae1@gwdg.de 
E2 and E3 classes. For classification of boards according to ETB guideline and the DIBt-100 (1994), the perforator method can also be used.

\section{Correction factor}

In accordance with EN 120, the measured perforator value depends on the moisture content of the boards. To compensate the influence of different moisture contents on the perforator value in the range $3 \% \leq \mathrm{u} \leq 9 \%$, the measured perforator values have to be adjusted to a moisture content of $6.5 \%$ by a formula published by Jann and Deppe (1990) as indicated in EN 312.

$$
F=-0.133 u+1.86
$$

where $F$ stands for the perforator correction factor and $u$ for the moisture content of the boards.

For boards with an emission level near or above $0.1 \mathrm{ppm}$, a strong correlation was found between the perforator values, adjusted to the values at a moisture content of $6.5 \%$ according to formula of Jann and Deppe (1990) in compliance with EN 120, and the emission level, as measured in $1-\mathrm{m}^{3}$ chamber for boards according to EN 717-1 (e.g. Roffael 1982; Mehlhorn 1986).

The empirical formula developed by Jann and Deppe (1990) is based on the assumption that boards bonded with different resins change their perforator values to the same extent irrespective of the molar ratio of the used resin or its possible chemical modification or any other added additives, which the resin may contain.

\section{Influence of molar ratio $\mathrm{U}: \mathrm{F}$}

Recent developments in the chemistry and technology of adhesives, especially of UF and MUF resins, created a new generation of low-fuming resins containing a formaldehyde/urea ratio $(\mathrm{F}: \mathrm{U})$ of $1: 1$ or even much lower. Boards containing such resins as a binder emit much less formaldehyde than the limit value of the E1-class (0.1 ppm according to EN 717-1). Boards with formaldehyde emission, well below the E1-limit show no strong or even satisfactory correlation between the perforator values, as measured by EN 120, and the emission in the chamber according to EN 717-1. Roffael et al. (2010) found that in such cases the correlation between the measured (uncorrected) perforator value and the emission in the chamber could even be stronger than between the corrected perforator values after Jann and Deppe (1990) and the emission, measured in the chamber according to EN 717-1.

This may be due to the fact that the empirical formula published by Jann and Deppe (1990) takes no account of the possible influence of the above-mentioned parameters (molar ratio of resin, modification of the resin) on the relationship between moisture content of the boards and the measured perforator values and consequently between the perforator value and the emission of the boards in the chamber (EN 717-1).

This work intends to show that the relation between the measured perforator value and the moisture content depends on other factors rather than the moisture content of the boards, particularly on the molar ratio of the resin. 


\section{Experimental work}

Six series of particleboards were prepared and stored at $20^{\circ} \mathrm{C}$ and different relative humidities; the extractable formaldehyde in the boards was then measured according to EN 120.

Preparation of boards

Six different UF resins of molar ratio F:U ranging between 1.096 and 0.945 , were prepared in the laboratory. Two of the resins were slightly modified with a low amount of melamine (4.5\%). The viscosities of the resins were between $300 \mathrm{mPa} \mathrm{s}$ and $450 \mathrm{mPa}$ s. The solids content of the resins was between 65.8 and $67.1 \%$. The characteristics of the resins are compiled in Table 1.

The resins were used to make particleboards of $16 \mathrm{~mm}$ thickness and $330 \mathrm{~mm} \times 500 \mathrm{~mm}$ size in the laboratory by using a resin loading of $8 \%$ in the face layer and $6.4 \%$ in the core layer. The hardener ammonium nitrate solution (50\%) was applied at $4 \%$ in the core and $1.5 \%$ in the surface (based on dry resin). Table 2 compiles the conditions used for the preparation of the boards.

Measurement of the perforator value

After preparation, the boards were conditioned at different relative humidities to attain various moisture contents; thereafter, the perforator values and moisture

Table 1 Characteristics of the used resins

\begin{tabular}{lllllll}
\hline Resin ID\# & Type & F/U & F/NH & Melamine \% dry & Dry content & Viscosity \\
\hline 1 & UF & 1.096 & 0.548 & 0 & 65.8 & 442 \\
2 & UMF & & 0.542 & 4.5 & 66.6 & 315 \\
3 & UF & 0.994 & 0.495 & 0 & 66.5 & 354 \\
4 & UMF & & 0.496 & 4.5 & 67.1 & 382 \\
5 & UF & 1.049 & 0.524 & 0 & 66.2 & \\
6 & UF & 0.945 & 0.473 & 0 & 66.5 & \\
\hline
\end{tabular}

Table 2 Conditions for board preparation

\begin{tabular}{lll}
\hline & Face & Core \\
\hline Resin dosage (\% dry/dry) & 8 & 6.4 \\
Hardener dosage (\% dry/dry) & 1.5 & 4 \\
Wood moisture content $(\%)$ & 2.7 & 1.9 \\
Theoretical moisture content $(\%)$ & 7.6 & 6.8 \\
Pressing time (min) & 2.7 & \\
Board size (mm) & $330 * 500 * 16$ & \\
Pressing temperature $\left({ }^{\circ} \mathrm{C}\right)$ & 185 & \\
\hline
\end{tabular}



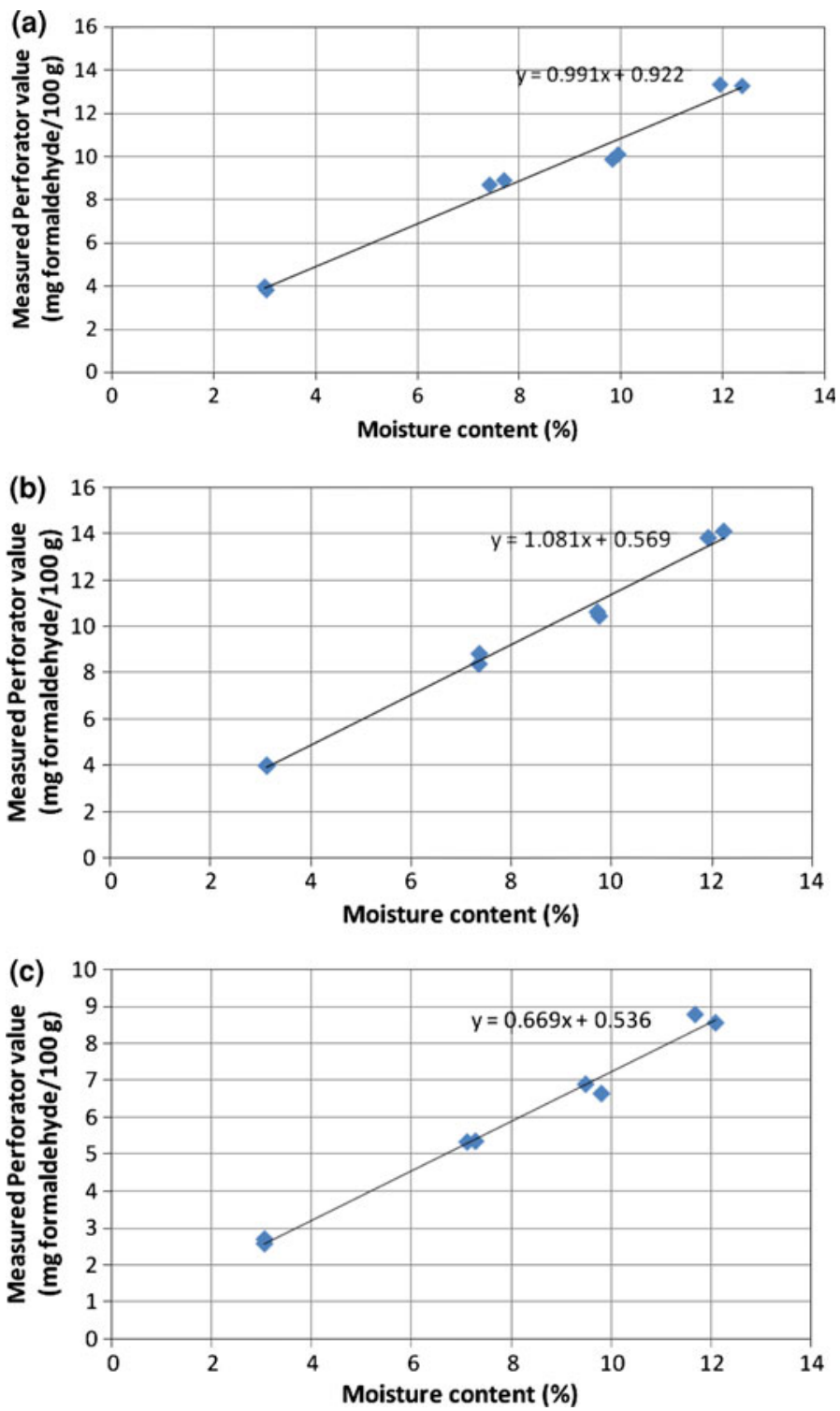

Fig. 1 Influence of moisture content on the perforator value for boards bonded with resins of different molar ratio $\mathrm{F}: \mathrm{NH}_{2} ;$ a 0.548 , b 0.542 , c 0.495 , d 0.496 , e 0.524 and f 0.473 . The result in Fig. 1b, d represents resins containing $4.5 \%$ melamine on dry basis

content of the boards were measured according to EN120 and plotted against the estimated moisture content for the boards bonded with the above-mentioned different resins. 

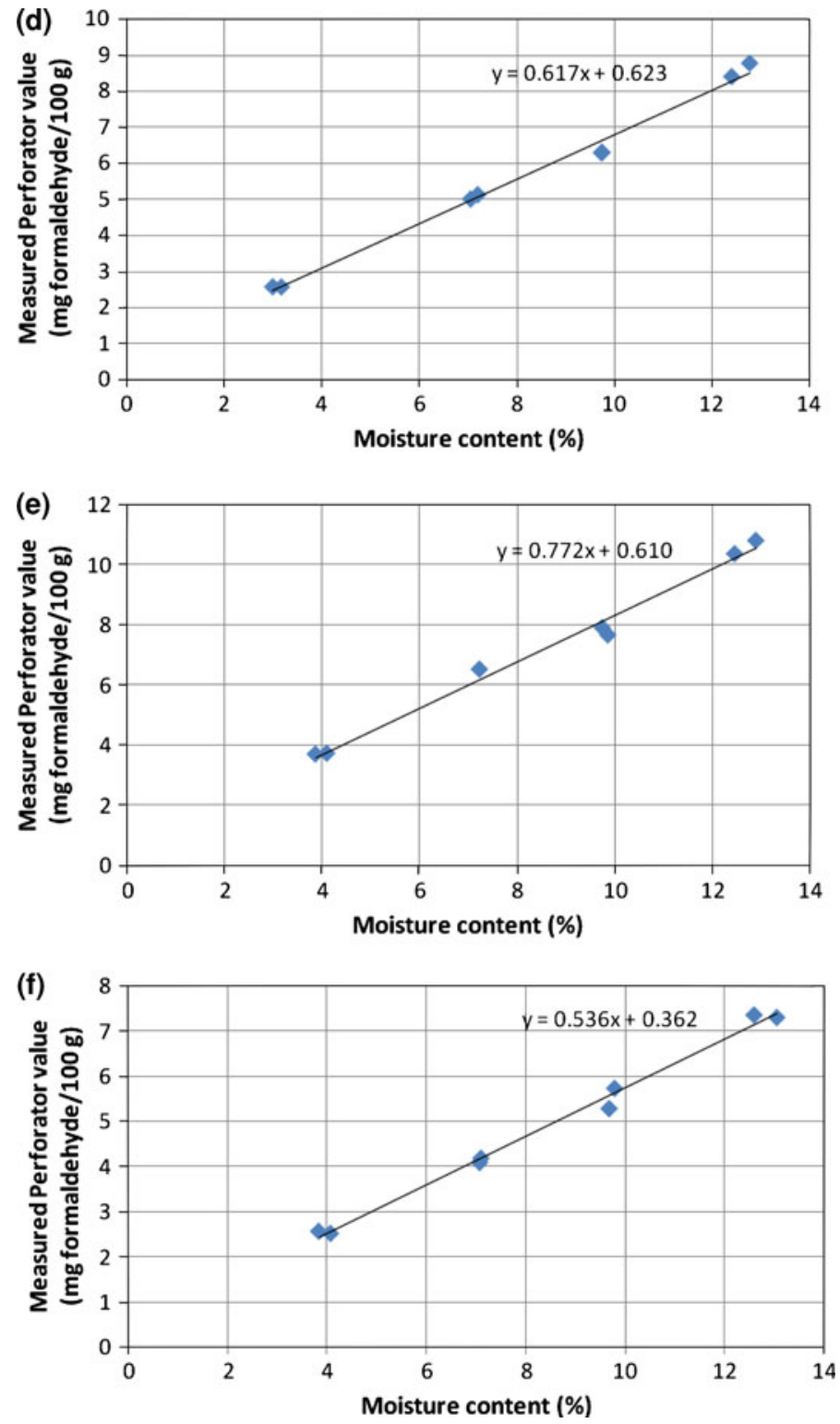

Fig. 1 continued

\section{Results and discussion}

As can be seen from the results in Fig. 1a-f, the relation between the measured perforator value and the moisture content of all the boards tested can be represented by a straight line. This is in line with the previous results on boards bonded with 
resins of high molar ratio published by Roffael and Mehlhorn (Roffael and Mehlhorn 1980). Moreover, the results in Fig. 1a-f reveal that the slope of the straight line representing the relationship between the moisture content and the perforator values depends highly on the molar ratio of the resin used. With decrease in the molar ratio $\mathrm{F}: \mathrm{NH}_{2}$, the slope of this straight line decreases remarkably. It lies by nearly 1 for resins of the molar ratio $\mathrm{F}: \mathrm{NH}_{2} 0.548$ and declines to about 0.536 for the resin with a molar ratio $\mathrm{F}: \mathrm{NH}_{2}$ 0.473. This means that the extent to which the measured perforator value changes with increase or decrease in the moisture content of the boards is highly dependent on the molar ratio of the resin used as a binder. This becomes obvious by plotting the molar ratio of the used resins against the measured perforator values. The curve in Fig. 2a shows a notable deviation from linearity, particularly in the low molar ratio region. This is in full agreement with the results published by Mayer (Mayer 1978), who also found a curvilinear relationship between the measured perforator value and the molar ratio with distinct deviation from linearity at low molar ratios. Likewise pronounced is the nonlinear relationship between the molar ratio and the slope of the different curves representing the relationships between the perforator value and the moisture
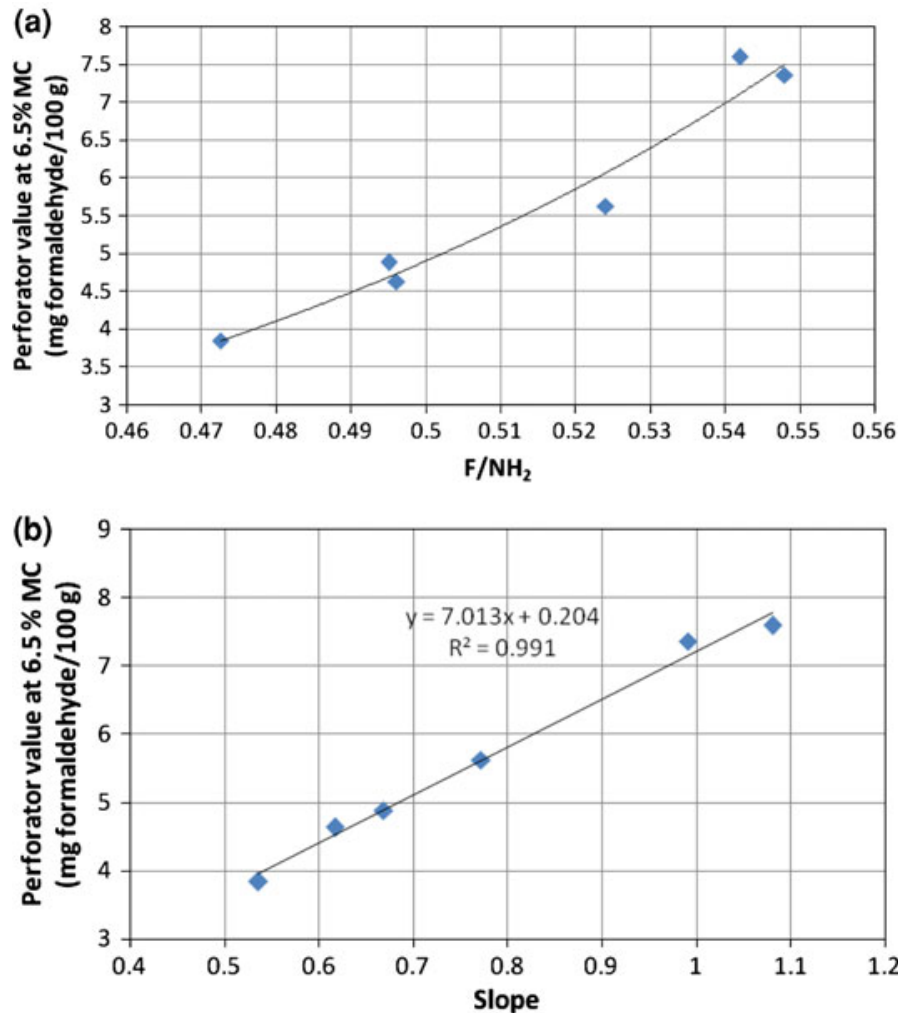

Fig. 2 Perforator value measured at $6.5 \%$ moisture content as a function of a the molar ratio and $\mathbf{b}$ slope of the fitted line representing the dependence of perforator value on moisture content (Fig. 1a-f) 
content. As it becomes evident from Fig. 2b, the slope of the curve showing the change in the perforator value against the molar ratio decreases as the value of $\mathrm{F}: \mathrm{NH}_{2}$ declines. The results in Fig. $2 \mathrm{a}$ and b including also resins 2 and 4, containing melamine, did not deviate, in the molar-ratio range investigated, from the results for the pure urea formaldehyde resins 1, 3, 5, and 6. Consequently, the low melamine content used in this investigation, which might well represent the addition used by resin manufacturers for fortifying low molar ratio resins for particleboard manufacturing, did not significantly influence the perforator value-moisture content relation.

The correction factor for each resin in the investigation was calculated using the linear relations presented in Fig. 1a-f. In Fig. 3, the calculated correction factor for the resin with the molar ratio $\mathrm{F}: \mathrm{NH}_{2} 0.548$ is presented, and Fig. 4 shows the results for the resin with the molar ratio $\mathrm{F}: \mathrm{NH}_{2}$ 0.473. The graphs also include the change of correction factor according to Jann and Deppe (1990). As it becomes evident from Figs. 3 and 4, the experimentally found and the currently used correction factors follow the same trend. However, the extrapolation of the straight line showing the dependence of the currently used correction factors leads to a correction factor near zero at a moisture content of $14 \%$. The deviation of the experimental result from the correction factor according to Jann and Deppe (1990) appears, according to the experimental results, to be independent of the molar ratio of the resin, since the deviation from the currently used equation in Figs. 3 and 4 is more or less in the same order of magnitude. Thus, the correlations of the "relative" perforator value versus moisture content are similar in the range of molar ratios used in this investigation.

Figure 5 shows the correction factor for all boards tested against the moisture content based on the measurements carried out in the laboratory. In Fig. 5, the correction factor according to Jann and Deppe is also included according to the equation $y=-0.133 \mathrm{u}+1.86$ passing through the values at $6.5 \%$ moisture content.

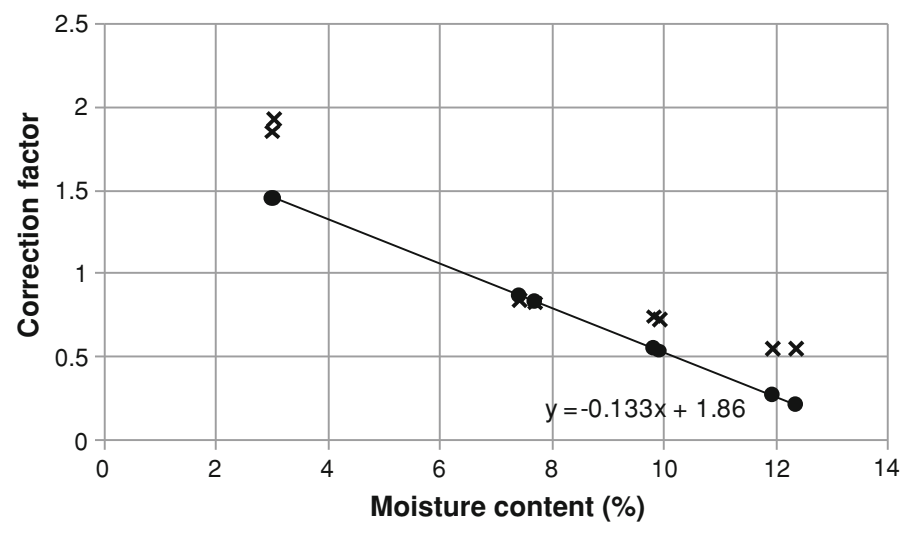

Fig. 3 Correction factors of the resin (molar ratio $\left.\mathrm{F}: \mathrm{NH}_{2}=0.548\right)$ Cross symbol correction factor based on results. Filled circle correction factor according to Jann-Deppe 


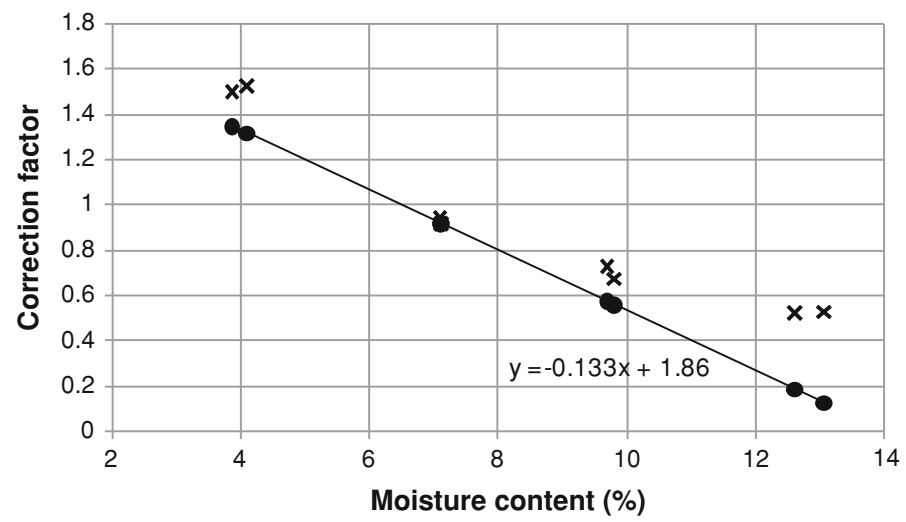

Fig. 4 Correction factors of the resin (molar ratio $\mathrm{F}: \mathrm{NH}_{2}=0.473$ ). Cross symbol correction factor based on results. Filled circle correction factor according to Jann-Deppe

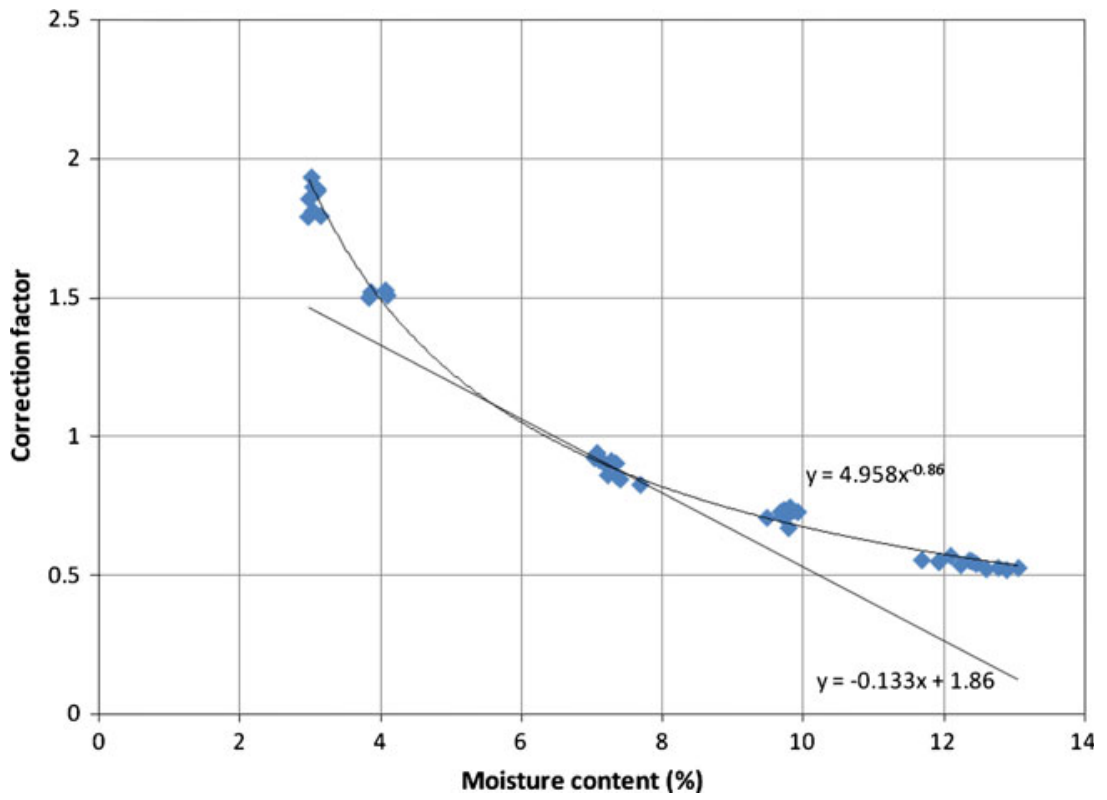

Fig. 5 Correction factors for all boards tested

Figure 6 shows that the correction factor is inversely proportional to the moisture content of the boards. The equation of Jann and Deppe leaves this fact unconsidered. Therefore, the correction factor developed by Jann and Deppe has to be modified to assess the formaldehyde release of particleboards adequately. The equation according to Fig. 6 might serve as a basis for further research in this field. Present investigation is limited to boards bonded by resins within the space of the 


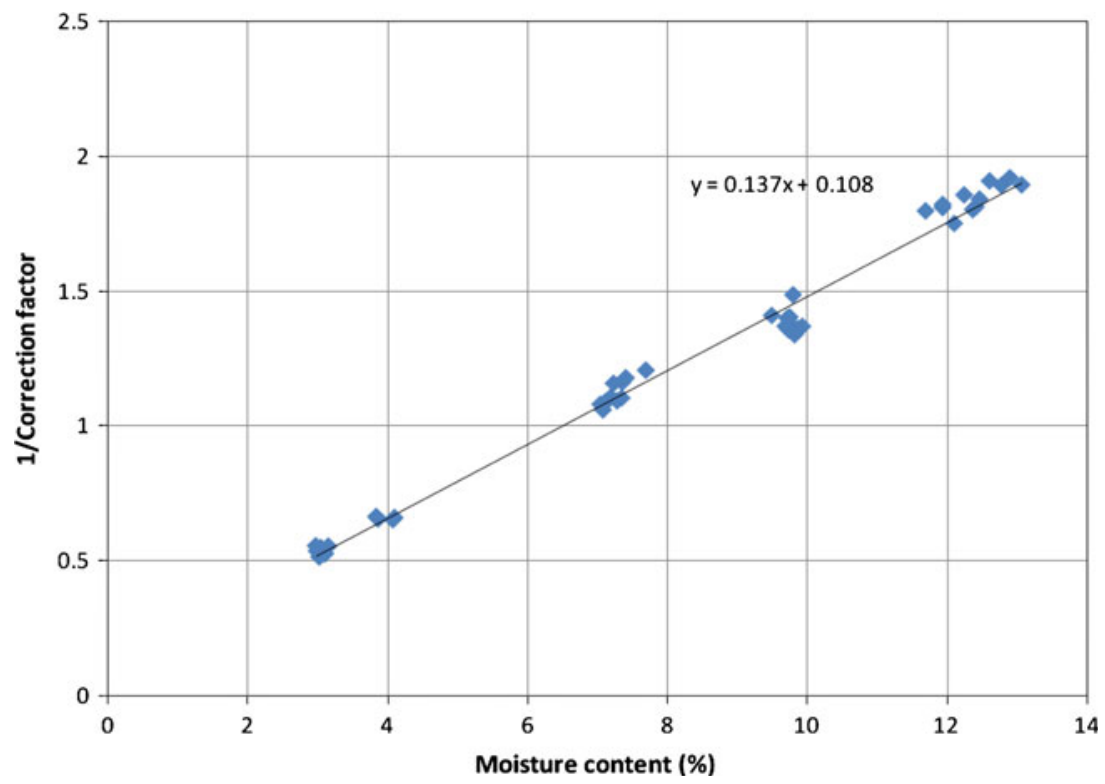

Fig. 6 Straight line showing the correction factors as inversely proportional to the moisture content

experimental design and tested only on particleboards. A new established correction factor developed according to the principles mentioned above might to some extent result in better correlation between chamber measurements and the perforator value. However, the shortcomings in the correlations between different emission methods in the low formaldehyde emission region still need to be addressed. A more accurate correction factor will result in a lower standard deviation in perforator measurement performed as quality control according to EN 326-2. As a consequence, the producer might be able to run the plant in an economically more efficient way, using more narrow safety margins with respect to perforator method.

\section{Conclusion}

The results of the experimental work clearly reassert that the rate of change of the measured perforator value with the moisture content of low emission UF-bonded boards also depends on the molar ratio $\left(\mathrm{F}: \mathrm{NH}_{2}\right)$ of the resin used to bond the boards. The correction factor to be applied for correcting the measured perforator value to the moisture content of $6.5 \%$ also depends on the moisture content, at which the perforator value was measured, according to an inversely proportional correlation, as indicated in part one of the work.

Open Access This article is distributed under the terms of the Creative Commons Attribution Noncommercial License which permits any noncommercial use, distribution, and reproduction in any medium, provided the original author(s) and source are credited. 


\section{References}

DIBt-100 (1994) Richtlinie über die Klassifizierung und Überwachung von Holzwerkstoffplatten bezüglich der Formaldehydabgabe (DIBt-Richtlinie 100), Deutsches Institut für Bautechnik, Beuth Verlag $\mathrm{GmbH}$

EN 120 (1992) Wood-based panels; determination of formaldehyde content; extraction method called perforator method, DIN German Institute for Standardization, Beuth Verlag GmbH

Jann O, Deppe HJ (1990) Zur Berücksichtigung der Materialfeuchte bei der Formaldehydmessung von Spanplatten. Holz Roh-Werkst 48:365-368

Mayer J (1978) Chemische Aspekte bei der Entwicklung formaldeydarmer Klebstoffe für die Holzwerkstoffindustrie. In: Spanplatten heute und morgen, DRW-Verlag, Stuttgart, pp 102-111

Mehlhorn L (1986) Normierungsverfahren für die Formaldehydabgabe von Spanplatten. Adhäsion 30(6):27-33

Roffael E (1982) Die Formaldehydabgabe von Spanplatten und anderen Werkstoffen. DRW-Verlag, Stuttgart, ISBN-Nr. 387181301

Roffael E (1993) Formaldehyde release from particleboard and other wood-based panels. Malayan Forest Records No. 37, ISBN:983-9592-15-7

Roffael E, Mehlhorn L (1980) Einfluß der Randbedingungen bei der Bestimmung des extrahierbaren Formaldehyds in Holzspanplatten nach der Perforatormethode. Holz Roh- Werkst 38:85-88

Roffael E, Johnsson B, Engström B (2010) On the measurement of formaldehyde release from lowemission wood-based panels using the perforator method. Wood Sci Technol 44:369-377

Salthammer T, Mentese S, Marutzky R (2009) Formaldehyde in the Indoor Environment. Chem Rev 2010 110(4):2536-2572 